\title{
Sharing human biobank samples and data in exchange for funding in South Africa in international collaborative health research - an ethicolegal analysis
}

\author{
M Maseme, ${ }^{1}$ BSc, BMedSc Hons, MScMed; S Mahomed, ${ }^{2}$ BCom, LLB, LLM, PhD \\ ${ }^{1}$ Steve Biko Centre for Bioethics, Faculty of Health Sciences, University of the Witwatersrand, and National Institute for Occupational Health, Division of \\ the National Health Laboratory Service, Johannesburg, South Africa \\ ${ }^{2}$ School of Law, Department of Jurisprudence, University of South Africa, Pretoria, South Africa
}

Corresponding author: M Maseme (masememr@gmail.com)

\begin{abstract}
The development of biobanks over the years has raised ethicolegal controversies and concerns, particularly in the context of cross-border transfers of human material. This is partly a result of inadequacies in national and international regulations in addressing these crucial aspects. It is common practice for South African biobanks and biobank researchers to seek funding from agencies that are independent of the biobank. These agencies often stipulate conditions requiring researchers to grant access to and share biomaterials and data as part of their agreements, in particular, in international collaborative health research. There is a need for the development of a national ethicolegal framework that addresses sharing biomaterials and data where funding is concerned, as a means of protecting biobank sample exploitation, researchers and participants.
\end{abstract}

S Afr J Bioethics Law 2020;13(2):103-107. https://doi.org/10.7196/SAJBL.2020.v13i2.719

Biobanks, defined by the World Medical Association (WMA) as collections of biomaterials (interchangeably referred to as samples) and associated data, ${ }^{[1]}$ have evolved in response to advances in sample preservation infrastructure and data storage technologies. ${ }^{[2]}$ This in turn has enabled the use of biobanking as a resource for supporting scientific research and development through readily available materials (including samples and data). The laws pertaining to biobanks and biobank research should reflect and be consistent with protection of materials as a means of preventing inappropriate sharing and access, thereby causing an infringement of ethical principles. Unlike morality, laws are enforceable. Health research in South Africa (SA) is regulated by a number of instruments, including: the Bill of Rights of the Constitution, 1996 (hereinafter referred to as the Constitution) ${ }_{1}^{[3]}$ which is supreme law; the National Health Act No. 61 of $2003(\mathrm{NHA})^{[4]}$ and its relevant research-related regulations; the Health Professions Council of SA (HPCSA)'s policies and professional codes of ethics (general and research-related); ${ }_{i}^{[5]}$ and the National Department of Health's Ethics in Health Research: Principles, Processes and Structures. ${ }^{[6]}$

Legislation differs between countries in as much as standards applicable in one society may not necessarily apply in another, hence the need for a specific and adequate national regulatory framework. In this article, the current ethicolegal framework for biobank research in SA is discussed, as well as material transfer agreements (MTAs) and regulations pertaining to the export of materials. The most relevant international regulations pertaining to the sharing of materials are highlighted as reference for development of a framework specific to $\mathrm{SA}$, and specific recommendations that address the current inadequacies are offered.

\section{Historical background and current context}

The increased development of biobanks and related research has given rise to a number of ethicolegal controversies linked to the sharing of materials that include, but are not limited to: privacy rights of participants; adequate participant and local researcher protections; ownership of materials and data; benefit sharing, informed consent; and secondary uses. Some well-known examples of genomic and biobank research initiatives that have a direct impact on the SA and African populations are the Human Heredity and Health in Africa (H3Africa) consortium, and Bridging Biobanking and Biomedical Research across Africa and Europe (B3Africa) initiatives. ${ }^{[7]}$ These initiatives have promised to transform the way researchers typically conduct international health research in Africa, via fostering equitable research collaborations. However, this has been met with criticism from African researchers involved in similar types of collaborations, who fear being exploited by their counterparts from high-income countries (HICs), for example, by not being included in benefit sharing. ${ }^{[7]}$ The H3Africa consortium developed a proposal requiring samples collected in projects to be shared for secondary use by one of its repositories. ${ }^{[8]}$ This proposal created considerable controversy and suspicion that this was a way in which H3Africa research was making African samples available for researchers elsewhere. H3Africa then developed a policy framework to address such fears. ${ }^{[8]}$ Another example is that of the University of the Witwatersrand Network for the Demographic Evaluation of Populations and their Health in Lowand Middle-Income Countries (Wits-INDEPTH) Collaborative Centre, known by the abbreviation AWI-Gen (Africa Wits INDEPTH partnership for Genomic Research) established under the auspices of H3Africa. ${ }^{[9]}$ 
On sample and data sharing, Ramsay et al. ${ }^{[9]}$ state that 'a characteristic of genomic research generally, and of our project more specifically, is that it usually involves international collaboration. In addition, funding conditions for AWI-Gen require us to make data and samples available for secondary analysis and use. It was recognised that there is a need to balance access with the interests of the participants, the ethics committees (in their capacity as protectors of participants) and the funders, and that sharing needed to be a two-way process.[9]

Commercialisation of biobank resources presents policy challenges for research participants, scientists and funders. ${ }^{[10]}$ Chapter 8, section 60 , of the NHA prohibits the selling of human samples as well as the donation of samples for financial gain, except for the reimbursement of reasonable expenses relating to the transfer of those samples. ${ }^{[4]}$

\section{Major ethical issues}

In this article, it is argued that sharing materials solely in exchange for funding is ethically wrong, based on the following premises:

(i) A risk of dual loyalty: In the specific situation of biobank and biobank research funding, the ethical dilemma would be potential violation of the research participant's dignity by researchers and biobank personnel being pressurised into exchanging the biomaterials and data for research funding. The absence of adequate legal and regulatory protections for research participants and those who have donated biobank samples creates room for infringement of ethical principles.

(ii) Infringement of ethical principles: In cases of unauthorised use of participant materials acquired by financial means, benefit sharing may be disregarded, hence beneficence and justice, as in fairness, are violated. Having participants' dignity infringed by exchanging their biomaterials and data for research funding would violate the principle of 'do no harm', albeit the harms are not physical.

(iii) Challenges to professionalism and the social contract between the participant and researcher: Some of the issues that challenge professionalism are economic factors, particularly financial pursuits that can undermine public trust in the practice of health research and healthcare. ${ }^{[1]}$ The integrity of the practice of biobanking and biobank research could become tainted when there are inadequate ethicoregulatory safeguards for protection of participant samples and data. When research participants trust researchers, by inference, they believe what they are being told. This has the potential to predispose participants or sample donors to exploitation, because of the vulnerability inherent in the trust relationship.

(iv) Infringement of cultural beliefs (cultural relativism): Spiritual beliefs within the SA population are the reason that some research participants object to their samples being shared with researchers in other countries. ${ }^{[12]}$

Treating research participants as a mere means to obtain funding, by providing their materials to sponsors, results in a maxim or rule that cannot be made universal. This formulation underscores the significance of personal autonomy, dignity and rights. Health research participants ought to be treated with the respect and moral dignity to which everyone is entitled. In preserving human dignity, participants should never be used as a means towards fulfilling others' interests.

\section{Current ethicolegal framework in SA}

Human rights related to the collection and storage of biobank materials that are listed in the Constitution ${ }^{[3]}$ are: the right to human dignity (section 10); the 'right not to be subjected to medical or scientific experiments without informed consent' (section 12(2)); and the 'right to privacy, which includes the right not to have the privacy of communications infringed' (section 14). ${ }^{[3]}$ These rights align with the ethical principle of respect for donor autonomy, and are also incorporated in the NHA. ${ }^{[4]}$ The deficiency in the NHA, however, is that although it provides for medical and scientific research, it lacks provisions for specific aspects pertaining to the collection and storage of materials for biobank purposes, as is discussed below. Neither does it provide for this in its regulations. However, recently in 2018, a National Material Transfer Agreement (NMTA $)^{[13]}$ was gazetted into law to provide for the transfer, use and processing of human biological materials. While it does include transfer of materials from biobanks, and storage into inter alia biobanks outside the country, it does not adequately address collection and sample storage. Section 60 of the NHA provides for protection of samples against commercialisation, and for an export permit for samples. The latter provision prohibits unauthorised export. There are, however, no provisions regulating conditions of funding. There are only research ethics-specific provisions in the subsequent chapter (chapter 9) of the NHA. The NHA regulations relating to tissue banks ${ }^{[14]}$ are silent with regard to biobanks. In these regulations, a tissue bank is defined as an institution or person that deals with providing a service for cell and tissue transplantation, ${ }^{[14]}$ which is clearly different from a biobank. The National Health Research Ethics Council (NHREC) guidelines, on the other hand, use the terms 'tissue bank' and 'repository' interchangeably, with no clear distinction or definition between the two. A repository is defined as the collection and storage of human biological materials such as blood, urine, bone marrow and other pathology samples for research purposes. ${ }^{[6]}$ Accordingly, ambiguity results when interpreting these definitions from a regulatory perspective. In addition, neither the NHREC nor the HPCSA guidelines address this crucial aspect of biobank regulations, and in particular, funding constraints to sample and data exchange.

\section{Material transfer agreements}

Institutional collaborations that involve sharing of materials require the use of agreements that are contractual, such as MTAs, as well as processes for sharing of such materials. An MTA is an agreement that documents and directs the transfer of materials between those involved, and it stipulates conditions under which the materials will be used, ${ }^{[13]}$ rights and responsibilities of the parties involved and terms that safeguard the rights of the participants. ${ }^{[15]}$ The purpose of biomaterial and associated data transfer, as well as restrictions for transfer, ought to be defined in an MTA, for example, prohibiting specimen sale, use in other projects or redistribution to third parties. In addition to an MTA, the governance structure of a biobank should include the criteria for biomaterial and data sharing. ${ }^{[2]}$ Prior to July 2018, SA biobanks were not required to use a national MTA. This resulted in there being no standardised framework or uniformity within which parties could engage in the use, transfer and processing of materials. This lack of uniformity was supported by research carried out by Moodley and Singh, ${ }^{[16]}$ whose study demonstrated 
that $S A$ researchers raised concerns and strong opinions regarding the lack of a national MTA. The concerns centred around little to no control on monitoring the fate of transferred samples, including claims that some researchers from HICs resisted using an MTA. Other concerns were a lack of consistency among African countries, in that not all have MTAs, and the fact that there exists varying legislation regarding cross-border transfer of samples, which challenges sample export. In SA, biomaterials can only be exported to other countries on condition of an export permit having being issued by the DirectorGeneral of Health in line with the regulations relating to the import and export of human tissue, blood, blood products, cultured cells, embryos, fetal tissue and zygotes. ${ }^{[17]}$ These regulations mandate that the amount of plasma intended for research purposes that can be exported does not exceed $5000 \mathrm{~mL}$. $^{[1]]}$ There is no mention of conditions and provisions for export of other types of biomaterials used in biobanks and health research. The regulations specifically indicate that issuing a permit for whole blood, frozen or fresh plasma, red-cell concentrate and platelet concentrate may only be to a Southern African Development Community (SADC) member state, provided that the requirements of the SA market needs have been met. ${ }^{[17]}$ This provision creates confusion and uncertainty, because these materials are usually used for therapeutic purposes such as blood transfusions rather than biobank or general health research, and also because the regulations are not explicit on whether such materials would be for research or therapeutic use. Tissue samples of less than $50 \mathrm{~g}$ intended for either therapeutic or research purposes are excluded from the provision of these regulations. ${ }^{[17]}$ Moreover, the wide range of biomaterials used for biobank and health research, which include other forms of genetic material besides DNA (which is only mentioned in the definition section and nowhere else in these regulations), are not stipulated within the regulations.

\section{Regulations relating to the export of materials in SA: Is the current export permit sufficient?}

The regulations relating to the import and export of human tissue are established in terms of section 68 of the NHA. ${ }^{[5]}$ They mandate researchers to obtain permit(s) prior to any imports and exports of human tissue. ${ }^{[17]}$ The export permit is subject to the conditions provided for by the NHA, and the legal requirements of the country to which the samples are being exported. Although there are protective measures for issued export permits that include a limited period of validity of the permit, which is 12 months (renewable), with no blanket authorisations issued, there are no limitations or conditions related to the export of samples. ${ }^{[18]}$

The NHREC, established in terms of section 72 of the NHA, is the regulatory authority for human and animal research. One of the responsibilities of the NHREC is to 'set norms and standards for conducting health research involving humans and animals (section (72) (6))! ${ }^{\prime[6]}$ There are currently no biobank-specific regulations in the SA ethico-legal framework, therefore different instruments are used to guide biobanking and biobank research. However, none of these provide for the regulating of funding. Neither is there any regulation of funding in the context of data sharing in international collaborative research. Moreover, the NHA does not address data sharing in international collaborations where funding is concerned. Furthermore, the NMTA does not refer to conditions of funding when transferring materials. Section 72 of the Protection of Personal
Information Act (POPIA) No. 2 of $2000^{[19]}$ protects persons from whom information has been collected by stipulating restrictions to crossborder transfer of personal information, unless there is certainty of similar legislative protections in the recipient country, where consent has been obtained and where it is to the benefit of such a person. Protection from commercialisation of data is, however, not addressed. In addition, neither the NHREC nor HPCSA guidelines address this crucial aspect of regulating biobanks or funding for sample and data exchange. The Intellectual Property Rights for Publicly Financed Research and Development (IPR) Act No. 51 of $2008^{[20]}$ applies to intellectual property arising from publicly financed research and development. Section 12 of the Act provides for commercialisation of intellectual property under two conditions, namely, if there is sufficient capacity locally to commercialise or develop the intellectual property, and if the transaction will benefit SA. Section 15 provides for private entities to become exclusive licensees of intellectual property if the entity meets the stated conditions, while co-ownership for intellectual property among research collaborators requires benefit sharing and commercialisation in the intellectual property agreement between collaborators. It is relevant to note, however, that the application of the IPR Act extends only to publicly funded research and development.

From the above analysis, it is evident that SA laws and regulations do not address sharing of materials where funding is concerned. In addition, the current export permit is insufficient in addressing ethicolegal issues around sample export. Considering the contextual complexities around issues of sample sharing, the key stakeholders that should be taken into account in this regard are the research participants whose materials have been collected. Taking into account the vast cultural diversity of Africans, it is important to seek views from such individuals. Few empirical studies have been conducted to address this issue. One study conducted in 2012 in two SA provinces revealed that approximately $78 \%$ of research participants were comfortable with their samples being stored, $12 \%$ insisted on having some knowledge of the reasons for such storage and $50 \%$ wanted to be re-contacted regarding consent for future use. ${ }^{[12]}$ Most participants (75\%) did not object to the export of their samples; however, $10 \%$ strongly objected, with concerns based on certain spiritual beliefs. A total of $39.5 \%$ of participants objected to any profits being generated from the research, and of this subgroup, $43 \%$ expressed a desire to share in the profits. Of the participants, $19.5 \%$ said that they would not mind if profits were generated from the research, provided that the research was conducted for the common good. ${ }^{[12]}$ Based on the inadequacy of SA laws and regulations, including the current export permit, in addressing the ethicolegal issues around sample export, development of regulations in this regard that meet international standards, is imperative.

\section{What amendments in the current export regulations are necessary?}

In order to address the deficiencies in the current export regulations for human samples, examples of biomaterials in SA biobanks, as well as the provisions for appropriate sample quantities that can be exported for each individual type or group of samples, should be included in the export regulations. Although the application form for an export permit allows for inclusion of any type of sample, as well as quantities, these two aspects are not provided for in the 
Table 1. International regulatory instruments and their key points on biomaterial and associated data transfer

\begin{tabular}{|c|c|c|}
\hline $\begin{array}{l}\text { Nature of } \\
\text { document }\end{array}$ & Title of document & Key point on material transfer \\
\hline Declaration & $\begin{array}{l}\text { WMA Declaration of Taipei On Ethical Considerations } \\
\text { Regarding Health Databases And Biobanks }{ }^{[2]}\end{array}$ & $\begin{array}{l}\text { Biobanks should include in their governance structures criteria and } \\
\text { procedures for access to and sharing of materials, including the use of } \\
\text { MTAs when necessary. }\end{array}$ \\
\hline Declaration & $\begin{array}{l}\text { WMA Declaration of Helsinki - Ethical Principles For } \\
\text { Medical Research Involving Human Subjects }\end{array}$ & $\begin{array}{l}\text { No provision on the conditions for sharing of materials by biobanks with } \\
\text { the collaborating centres where funding is concerned. }\end{array}$ \\
\hline Guidelines & $\begin{array}{l}\text { CIOMS International Ethical Guidelines for Health- } \\
\text { Related Research Involving Humans }{ }^{[2]}\end{array}$ & $\begin{array}{l}\text { Provides guidance for the use of an MTA for the transfer of biomaterials, } \\
\text { which should include the duration and fate of samples. Data sharing } \\
\text { should also be covered in agreements that protect privacy of the } \\
\text { participants. }\end{array}$ \\
\hline Declaration & $\begin{array}{l}\text { OECD Declaration on Access to Research Data from } \\
\text { Public Funding }\end{array}$ & $\begin{array}{l}\text { Recommends consideration for explicit agreements for data access } \\
\text { between collaborating centres with no provision for conditions of access } \\
\text { to and sharing of materials. }\end{array}$ \\
\hline Guidelines & $\begin{array}{l}\text { OECD Guidelines for Human Biobanks and Genetic } \\
\text { Research Databases }{ }^{[24]}\end{array}$ & $\begin{array}{l}\text { The criteria for access of materials should be clear and in accordance } \\
\text { with consent granted by the participant. }\end{array}$ \\
\hline Best practices & $\begin{array}{l}\text { ISBER Best Practices: Recommendations for } \\
\text { Repositories }{ }^{[25]}\end{array}$ & $\begin{array}{l}\text { Recommends adherence to local regulations pertaining to sharing of } \\
\text { genetic data. }\end{array}$ \\
\hline Regulation & European Union's GDPR ${ }^{[26]}$ & $\begin{array}{l}\text { Data sharing for scientific research can only be done if the participant } \\
\text { has been informed with appropriate safeguards for participant rights, } \\
\text { including pseudonymisation of the data (section 156) as well as } \\
\text { collection for a specified purpose (article 6). }\end{array}$ \\
\hline
\end{tabular}

WMA $=$ World Medical Association; MTA = material transfer agreement; $C$ IOMS = Council for International Organizations of Medical Sciences; $\mathrm{OECD}=$ Organisation for Economic Co-operation and Development; ISBER = International Society for Biological and Environmental Repositories; GDPR = General Data Protection Regulation.

regulations. A clear distinction should also be made in terms of provisions for export of samples that are used for general health research, including biobank research, and samples that are used for therapeutic purposes. In addition, as the cross-border sharing of samples raises a variety of complicated ethical and legal issues (e.g. informed consent, ownership, data protection), the regulations should attempt to address these and create a minimum standard.

\section{International regulations and guidelines}

Biobanks are governed by the national laws and regulations of the countries in which they are physically located. However, international regulations also have an influence on the various ethical aspects of biobank processes. The list of the various international regulatory instruments for the governance of biobanks below is by no means exhaustive; however, they include:

- the WMA Declaration of Taipei On Ethical Considerations Regarding Health Databases and Biobanks ${ }^{[2]}$

- the WMA Declaration of Helsinki - Ethical Principles for Medical Research Involving Human Subjects ${ }^{[21]}$

- the Council for International Organizations of Medical Sciences' International Ethical Guidelines for Health-Related Research Involving Humans ${ }^{[2]}$

- the Organisation for Economic Co-operation and Development (OECD) Guidelines for Human Biobanks and Genetic Research Databases $^{[23]}$

- the OECD Principles and Guidelines for Access to Research Data from Public Funding ${ }^{[25]}$

- the International Society for Biological and Environmental Repositories Best Practices: Recommendations for Repositories ${ }^{[25]}$

- the European Union's General Data Protection Regulation (GPDR). ${ }^{[26]}$
The key points in each of the identified international regulatory instruments pertaining to biomaterial and associated data sharing are illustrated in Table 1, and include: (i) guidance on criteria and procedures for material sharing in biobank governance structures; (ii) guidance on the duration of MTAs as well as the fate of transferred materials; and (iii) consideration of material access in accordance with consent granted by the participant. Other identified instruments do not provide any guidance on sample and data transfer.

\section{Recommendations}

In order to address the inadequacies in the current SA regulatory landscape on sharing human materials in exchange for funding in SA, particularly in the context of international collaborative health research, the following amendments ought to be made:

(i) There ought to be amendments in the current ethicoregulatory structure to provide for conditions under which biomaterials and data can be shared with funders, in order to protect participants' rights. These should include stipulations prohibiting sharing of materials as a condition of funding, for example, prohibiting specimen sale, use in other projects or redistribution to third parties, coupled with a comprehensive regulatory framework that covers protections of the material when it is in the hands of the recipient institution.

(ii) Based on the inadequacies in the current export regulations for biobank cross-border transfer, an inclusion of biobank sample export in the current regulations should cover the wide array of biobank samples, as well as provide a clear distinction between pathology samples and those that are for therapeutic use.

(iii) A recommendation to address the ethicolegal framework that provides for the conditions and restrictions for sharing of materials with the funder as a way of optimising participant 
protection would either be the development of a separate MTA for collaborations where funding is concerned, or an amendment of the current NMTA to include these aspects.

\section{Conclusion}

The sharing of biobank materials raises several ethicolegal concerns, particularly in the context of cross-border transfers, where the concerns arise mainly as a result of inadequacies in national and international regulations addressing these crucial aspects. While international regulations are often explicit with recommendations for individual countries to develop more specific regulations for participant protections where samples are shared with third parties, the onus is on the respective countries themselves to formulate and implement such regulations. Until such a time exists where these inadequacies have been addressed, the competing interests of stakeholders involved in sharing materials ought to be discussed at the beginning of such collaborations, with mutually agreed terms as a requirement, especially where funding is concerned.

Declaration. This work forms part of MM's MSc titled 'Sharing of biomaterials and data for biobank use in exchange for funding in South Africa in international collaborative health research: An ethicolegal analysis.' MM would like to acknowledge her Master's supervisor, Prof. S Mahomed, and advice provided by Prof. A Dhai (Steve Biko Centre for Bioethics, University of the Witwatersrand, SA).

Acknowledgements. The National Health Laboratory Service for funding MM's MSc and the University of the Witwatersrand for funding publication of this article.

Author contributions. MM conceived the idea, conducted the research and drafted the manuscript. SM assisted with the development of arguments, review and edits as well as provided supervisory input.

Funding. The University of the Witwatersrand funded the publication. Conflicts of interest. None.

1. World Medical Association. Declaration of Taipei on Ethical Considerations Regarding Health Databases and Biobanks. WMA, 2016. https://www.wma.net/ policies-post/wma-declaration-of-taipei-on-ethical-considerations-regarding health-databases-and-biobanks/ (accessed 3 February 2020).

2. De Souza YG, Greenspan JS. Biobanking past, present and future: Responsibilities and benefits. AIDS 2013;27(3):303-312. https://doi.org/10.1097\%2FQAD.0b013e $32835 \mathrm{c} 1244$

3. Constitution of the Republic of South Africa, 1996. Government Gazette 17678 of 18 December 1996.

4. South Africa. National Health Act No. 61 of 2003. Government Gazette 26595 of 23 July 2004.

5. Health Professions Council of South Africa. Guidelines for good practice in the healthcare professions: General ethical guidelines for health researchers. Booklet 13. Pretoria: HPCSA, 2016. https://cdn.sada.co.za/files/clinical-resources/ hpcsa/HPCSA\%20Booklet\%2013\%20Gen\%20Ethical\%20Guidelines\%20for\%20 Health\%20Researchers.pdf?v=20191004094352 (accessed 3 February 2020).

6. National Department of Health, South Africa. Ethics in health research: Principles, processes and structures. http://nhrec.health.gov.za/index.php/grids-preview (accessed 3 February 2020).
7. Munung NS, Mayosi BM, De Vries J. Equity in international health research collaborations in Africa: Perceptions and expectations of African researchers. PLoS One 2015;12(10):1-17. https://doi.org/10.1371/journal.pone.0186237

8. De Vries J, Tindana P, Littler K, et al. The H3Africa policy framework: Negotiating fairness in genomics. Trends in Genetics 2015;31(3):117-119. https://doi. org/10.1016/j.tig.2014.11.004

9. Ramsay M, De Vries J, Soodyall H, et al. Ethical issues in genomic research on the African continent: experiences and challenges to ethics review committees. Human Genomics 2014;8(15):1-6. https://doi.org/10.1186\%2Fs40246-014-0015-x

10. Caulfield T, Burningham, $S$, Joly $Y$, et al. A review of the key issues associated with the commercialisation of biobanks. J Law Biosci 2014;1(1):94-110. https://doi. org/10.1093\%2Fjlb\%2Flst004

11. Dhai A, McQuoid-Mason D. Consent. In: Dhai A, McQuoid-Mason D, editors Bioethics, Human Rights and Health Law: Principles and Practice. 1st ed. Cape Town: Juta \& Company Ltd, 2011:69-86.

12. Moodley K, Sibanda N, February K, et al. 'It's my blood': ethical complexities in the use, storage and export of biological samples: Perspectives from South African research participants. BMC Medical Ethics 2014;15(4):1-7. https://doi. org/10.1186/1472-6939-15-4

13. South Africa. National Health Act No. 61 of 2003. Material Transfer Agreement of Human Biological Materials. Government Gazette 41781 of 20 July 2018.

14. South Africa. Regulations Relating to Tissue Banks. R182, Government Gazette 35099 of 2 March 2012

15. Bennett AB, Streitz WD, Gacel RA. Specific Issues with Material Transfer Agreements. Handbook of Best Practices. Oxford: MIHR, 2007:693-716.

16. Moodley K, Singh S. 'It's all about trust': Reflections of researchers on the complexity and controversy surrounding biobanking in South Africa. BMC Med Ethics 2016;17(57):1-9. https://doi.org/10.1186/s12910-016-0140-2

17. South Africa. Regulations relating to the import and export of human tissue, blood, blood products, cultured cells, stem cells, embryos, fetal tissue, zygotes and gametes. R 181, Government Gazette 35099 of 2 March 2012.

18. University of Cape Town. Frequently Asked Questions (FAQs) Import/Export Permit Programme. https://vula.uct.ac.za/access/content/group/25f04c1d-1bf4497a-bdb5-e12357b066ef/test/FAQs\%20\%20PERMIT\%20PROGRAMME\%20 MARCH\%202015.pdf (accessed 10 June 2019).

19. South Africa. Protection of Personal Information Act No. 4 of 2013. Government Gazette 37067 of 26 November 2013.

20. South Africa. Intellectual Property Rights from Publicly Financed Research and Development Act No. 51 of 2008.

21. World Medical Organization, WMA Declaration of Helsinki - Ethical Principles for Medical Research Involving Human Subjects adopted by the 18th WMA General Assembly, Helsinki, Finland, June 1964 and amended by the 64th WMA Genera Assembly, Fortaleza, Brazil, October 2013. https://www.wma.net/policies-post/ wma-declaration-of-helsinki-ethical-principlesfor-medical-research-involvinghuman-subjects/ (accessed 3 February 2020).

22. Council for International Organizations of Medical Sciences. International Ethical Guidelines for Health Related Research Involving Humans. CIOMS, 2016. https:// cioms.ch/wp-content/uploads/2017/01/WEB-CIOMS-EthicalGuidelines.pdf (accessed 10 February 2020).

23. Organisation for Economic Co-Operation and Development. OECD Guidelines on Human Biobanks and Genetic Research Databases. OECD, 2009. http://www. oecd.org/sti/emerging-tech/44054609.pdf (accessed 13 February 2020).

24. Organisation for Economic Co-operation and Development. Principles and Guidelines for Access to Research Data from Public Funding. OECD, 2007. http:// www.oecd.org/sti/inno/38500813.pdf (accessed 13 February 2020).

25. International Society for Biological and Environmental Repositories. Best Practices: Recommendations for Repositories. ISBER, 2018. https://c.ymcdn.com/ sites/isber.site-ym.com/resource/resmgr/Best_Practices 4th_Edition/ISBER Best_Practices_Recomme.pdf (accessed 13 February 2020).

26. EUR-Lex, Regulation (EU) 2016/679 of the European Parliament and of the Council of 27 April 2016 on the protection of natural persons with regard to the processing of personal data and on the free movement of such data, and repealing Directive 95/46/EC (General Data Protection Regulation). https://eurlex.europa.eu/eli/reg/2016/679/0j (accessed 7 June 2020.

Accepted 20 August 2020. 